\title{
Rheological study of an extruded fish diet with the addition of hydrolyzed protein meal
}

\author{
José Luis Hoyos-Concha ${ }^{1}$, Héctor Samuel Villada-Castillo', Alejandro Fernández-Quintero² and Rodrigo Ortega- \\ Toro $^{3^{*}}$
}

\begin{abstract}
${ }^{1}$ Agroindustry Department, Agroindustrial Engineering Program, Agroindustrial Byproducts Exploitation Research Group (ASUBAGROIN) and Research Group of Science and Technology of Agroindustrial Interest Biomolecules (CYTBIA), Universidad del Cauca, Calle 5 No 4 - 70, Popayán, Colombia.

${ }^{2}$ School of Food Engineering, Faculty of Engineering, Research Group in Agri-Food and Biotechnological Process Engineering (GIPAB), Universidad del Valle, Ciudad Universitaria Meléndez Calle 13 \# 100-00, Cali, Colombia.

${ }^{3}$ Food Engineering Department, Food Packaging and Shelf Life Research Group (FP\&SL) and Complex Fluids Engineering and Food Rheology Research Group (IFCRA), University of Cartagena, Avenida Consulado Calle 30 No. 48-152, Cartagena de Indias, Colombia.

* Corresponding author: rortegap1@unicartagena.edu.co
\end{abstract}

\begin{abstract}
The extrusion of food for human and animal consumption is a unit operation that includes mixing, shearing and force to the materials related to the rheological properties of the materials in the extruder. The present work aims to study the rheological behavior of an extruded fish diet incorporating hydrolyzed protein flour processed by extrusion. The measurement was carried out online with a slit die rheometer, defining the rheological models and parameters that fit the process. During the extrusion process, the raw materials used were hydrolyzed protein meal, fish meal and cassava starch. For the results, the evaluated treatments were adjusted to the Power Law, where an increase in the shear rate decreases the viscosity of the material, corresponding to a pseudoplastic behavior. The incorporation of hydrolyzed protein flour presented a significant effect on the value of $\mathrm{n}$ and Klp, increasing the viscosity with the increase in the percentage of inclusion of $\mathrm{HPH}$. The models obtained for the prediction of the viscosity are adjusted to the changes in shear rate, temperature and humidity of the system.
\end{abstract}

Keywords: Hydrolyzed protein flour; Cassava starch; In-line rheology; Power law; Pseudoplastic

\section{Introduction}

The extrusion cooking of food for human and animal consumption is a unitary operation in which various products are produced from starchy raw materials, animal or vegetable origin, and oilseeds. Products for animal feed, especially for fish farming, are an example of these extruded products, which under high temperature and short time cooking conditions (HTST), mixing, shearing, and forcing the materials are carried out through a nozzle designed to form the product, processes strongly related to the rheological properties of the materials in the extruder [1].

Since the raw materials used in animal diets have different rheological properties, their understanding can facilitate the optimization of processing methods, process control, and product quality. And the quality of the finished product, such as texture, flavor release, stability, appearance, among others [2]. Apparent viscosity is one of the most important rheological properties of raw materials of non-Newtonian biological origin, being a variable used for the engineering analysis of extrusion [3], mainly in aspects of the behavior of the fluid during processing. Viscosity is related to composition and process variables during extrusion [4]. 
In extrusion processes, structural changes of the components occur since biopolymers such as starch and proteins are susceptible to high temperatures or mechanical stress [5] , which under suitable conditions increase the digestibility of the macromolecules [6]. The starch will generate an increase in gelatinization and breakdown of its chains forming dextrins, and the proteins will take place the unfolding of their structure and breaking of intermolecular bonds yielding peptides of different molecular weight, establishing molecular interactions between terminal groups of the protein and starch molecules. These changes that occur during the extrusion process affect the behavior of the fluid and can be measured, facilitating product quality assurance.

Different techniques have been used to carry out rheological measurements, which vary according to whether the determination is carried out offline (off-line) or if the size is carried out online (in-line). In the first case, the experimental conditions can be applied mainly through capillary rheometers; these measurements are made with higher water contents, so the determined viscosity is lower than that developed directly in an extruder [7]. With in-line measurement systems, measurement is performed by coupling a device to the extruder outlet [8],[9],[10],[7],[11], achieving measurements that avoid structural changes and water loss during the height [12]. Both the cylindrical type die (rod die) and the slit type die (slot die) can be directly coupled to the extruder, achieving different shear rate with the screw speed, achieving broader ranges of shear rate [13],[14].Regardless of the technique used to determine the rheological behavior under extrusion firing, it has been established that molten materials are essentially pseudoplastic whose rheological behavior can be adequately adjusted to a Power Law model [1],[14], [15] The first rheological model proposed to explain the behavior of cereal masses melted by extrusion was Harper's [9], which assumes that the group behaves as a pseudoplastic fluid, according to the Power Law model, with dependence to change in temperature of the Arrhenius type and an exponential sensitivity to change in water content [7].

The present work aims to study the rheological behavior of an extruded fish diet incorporating hydrolyzed protein flour processed by extrusion. The measurement was carried out online with a slit die rheometer, defining the rheological models and parameters that fit the process.

\section{Materials and Methods}

\section{Raw Materials}

The raw materials used for the evaluation during the extrusion process were hydrolyzed protein flour, fish flour (Siquality SA, Guayaquil-Ecuador), and cassava starch (Sucre starch); their chemical composition is described in Table 1. Additives such as vitamin core formulated for fish farming (Premex), Bentonite (Premex), calcium carbonate (CaCO3) (analytical grade 99\%, Carlo Erba), and sodium chloride $(\mathrm{NaCl})$ (analytical grade 99\%, Carlo Erba) were incorporated into the diet.

Table 1. Chemical composition of raw materials on a dry basis (b.s).

\begin{tabular}{cccc}
\hline & Hydrolyzed protein flour & Fish flour & Cassava starch \\
& & & \\
\hline Moisture $(\%, \mathbf{m} / \mathbf{m})$ & $\mathbf{5 . 0 5} \pm \mathbf{0 . 0 2}$ & $\mathbf{5 . 1 5} \pm \mathbf{0 , 0 8}$ & $12.86 \pm 0.03$ \\
\hline Total protein $(\%, \mathrm{~m} / \mathrm{m})$ & $62.92 \pm 0.05$ & $63.20 \pm 0.06$ & $1.60 \pm 0.05$ \\
Ethereal extract $(\%, \mathrm{~m} / \mathrm{m})$ & $6,45 \pm 0.02$ & $6.81 \pm 0.02$ & 0 \\
Ashes $(\%, \mathrm{~m} / \mathrm{m})$ & $17.86 \pm 0.12$ & $18.67 \pm 0.14$ & 0 \\
Fiber $(\%, \mathrm{~m} / \mathrm{m})$ & $0.6 \pm 0.2$ & $1.0 \pm 0.2$ & $2.16 \pm 0.04$ \\
\hline
\end{tabular}




\begin{tabular}{cccc}
\hline Nitrogen-free extract & 12.2 & 10.3 & 96.24 \\
$($ ELN) $(\%, \mathrm{~m} / \mathrm{m})$ & & & \\
Degree of hydrolysis & $62.948 \pm 0.011$ & $5.61 \pm 0.05$ & \\
$(\%, \mathrm{~m} / \mathrm{m})$ & $68.94 \pm 0.09$ & $17.33 \pm 0.06$ & \\
Soluble protein $(\%, \mathrm{~m} / \mathrm{m})$ & & \\
\hline
\end{tabular}

\section{Diet formulation}

Its incorporation was evaluated in a range between 15 and $35 \%$ as a substitute for fish meals. The starch source, vitamin nucleus, and minerals remained stable (Table 2) and were supplemented according to the requirements reported by the National Research Council.

Table 2. Raw materials required for the preparation of the diet.

\begin{tabular}{cc}
\hline Raw materials & inclusion (\%) \\
\hline Cassava starch & 55.0 \\
Hydrolyzed protein flour & $15.0-35.0$ \\
Fish flour & $25.0-5.0$ \\
Vitamin nucleus & 2.0 \\
Calcium carbonate & 0.8 \\
Bentonite & 1.7 \\
Sodium chloride & 0.5 \\
\hline
\end{tabular}

Isoprotein and isoenergetic diets were obtained, formulated for omnivorous fish in the fattening stage. The flours were sieved through a Tyler series No. 40 sieves and mixed in a Kitchen Aid mixer for 30 minutes. Later, they were packed in polyethylene bags and refrigerated for 24 hours to be evaluated.

\section{Rheological measurement using an in-line slit die rheometer}

A Thermo Scientific (Germany) brand slit dies to type vertical line rheometer was used to measure the rheological properties of mixtures, including hydrolyzed protein flour, with an outlet opening of $1.5 \times 20 \mathrm{~mm}$, with ports for a melt temperature sensor and three pressure sensors (700, 500 and 300 bar) (see figure 1), coupled to a compact single screw extruder, Haake Polylab OS Rheomex 19/25 OS (Germany), which consists of a 475 $\mathrm{mm}$ long (L) and $19 \mathrm{~mm}$ diameter (D) worm with a 25: $1 \mathrm{~L} / \mathrm{D}$ ratio, a maximum working temperature of $450 \mathrm{oC}$, a maximum speed of $250 \mathrm{~min}-1$ and a maximum torque of $160 \mathrm{Nm}$, coupled to a Haake RheoDrive 4 system, with a motor power of $4 \mathrm{~kW}$. The feeding was carried out using the HAAKE Metering Feeder OS.
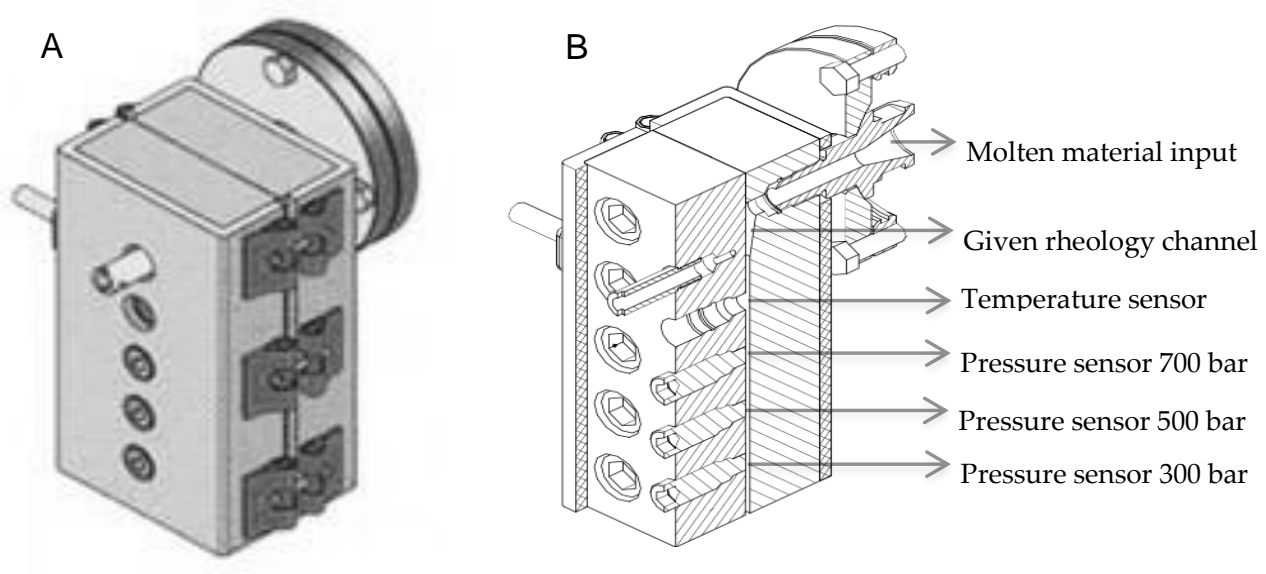

Source: Adapted from Thermo Scientific

Figure 1. Inline slit die rheometer a. General view b. Longitudinal cut. 
The temperature and the range of working speeds were adjusted between 160 and 250 min-1, obtaining four samples (160, 190, 220, and 250), which were weighed, and the values were recorded in the PolySoft OS Capillary Rheology software for MS. Windows.

The determination of the volumetric flow rate was carried out by quantifying the density of the melt. The measurement was carried out according to the ASTM D12382004c standard, in a Tinius Olsen model MP 1200 (Germany) plastometer, composed of a vertical cylinder, a die with a $2.095 \mathrm{~mm}$ hole diameter and $8 \mathrm{~mm}$ long. The test temperature was adjusted to $115^{\circ} \mathrm{C}$ with $3.6 \mathrm{~kg}$ of weight on the piston, with a preheating time of $30 \mathrm{~s}$. The travel meter was adjusted to $6.35 \mathrm{~mm} \pm 0.25 \mathrm{~mm}$, the plastometer was loaded with an $8 \mathrm{~g}$ sample, the sample was made to flow through the die, and the weight was recorded for five examples for each material, obtaining the values of volumetric melt index, mass melt index and melt density. According to the following equations, the parameters evaluated were shear rate, shear stress, and apparent viscosity [16].

$\gamma_{a p p}=\frac{6 \cdot Q}{W \cdot H^{2}}$

where is the apparent shear rate $\left(\mathrm{s} \gamma_{a p p}{ }^{-1}\right), Q$ is the volumetric flow rate $\left(\mathrm{m}^{3} / \mathrm{s}\right)$, is the width of the slit $(\mathrm{m})$ and $W H$ is the height of the slit (m) (Eq.1).

$$
\tau=\frac{\Delta P \cdot H}{2 \cdot L}
$$

is the shear stress $(\mathrm{Pa}), \Delta P$ is the pressure variation in the capillary $(\mathrm{Pa})$ and $\mathrm{L}$ the length of the cleft (m) (Eq. 2).

$$
\gamma_{\text {true }}=\frac{1}{3} \cdot \gamma_{a p p} \cdot\left(2+\frac{\partial \log \gamma_{a p p}}{\partial \log \tau}\right)
$$

The correction of the shear rate was performed using the Weissenberg-Rabinowitsch equation (Eq. 3).

$$
\eta_{\text {app }}=\frac{\tau}{\gamma_{\text {true }}}
$$

$\eta_{a p p}$ is the apparent viscosity (Pa.s) quantified as the relationship between shear stress and true shear velocity (Eq. 4$)$.

The rheological behavior of the samples was represented by the Power Law (), Bingham () and Casson () models (Eq. 5, 6, 7).

$$
\begin{gathered}
\tau=K_{l p} \gamma^{n} \\
\tau=\tau_{0 b g}+K_{b g} \gamma \\
\tau^{0.5}=\tau_{0 c s}^{0.5}+K_{c s} \gamma^{0.5}
\end{gathered}
$$

Where $K_{l p}, K_{c s}, \mathrm{y} K_{b g}$, are the consistency indices of the samples; corresponds to the minimum force to initiate the flow through the capillary 0 [17].

The selected model was made according to the standard error (Eq. 8)

$$
\left[\Sigma\left(X_{m}-X_{c}\right)^{2} /(N-2)^{2}\right]^{0.5} / \text { rango } x 1000 \quad \text { (Eq. 8) }
$$

Where $X_{m}$ is the measured value; $X_{c}$ is the calculated value; $N$ is the number of data and range is the maximum value - minimum value of $X_{m}$.

\section{Statistical analysis}

A 3k factorial design was used where the factors temperature, humidity, and inclusion of HPH were evaluated, with three levels each, as described in Table 3. The results of the factorial design were analyzed by analysis of variance with a value of $p<0.05$, and the data were processed in the Minitab V.16 software. A mean comparison analysis was performed with the Tukey test at $\mathrm{p}<0.05$, for statistically significant data.

$$
\eta=K_{l p} \cdot \gamma^{n-1} \cdot \exp \left[\frac{\Delta E}{R} \cdot\left(\frac{1}{T}\right)+b \cdot(M C)\right]
$$

The experimental values obtained were adjusted to harper's rheological regression model (Eq. 9). $\eta$ is the apparent viscosity (Pa.s), $K_{l p}$ is the consistency index (Pa.s $\left.{ }^{\mathrm{n}}\right), n$ is 
the flow behavior index, $\gamma$ is the shear rate $\left(\mathrm{s}^{-1}\right), \Delta E$ is the activation energy $(\mathrm{J} / \mathrm{mol}), \Delta E$ is the constant ideal gases $(\mathrm{J} / \mathrm{mol} \mathrm{K}), T$ is the temperature $(\mathrm{K}), M C$ is the mass fraction of water (b.h) and the parameter $b$ relates the change in moisture content in the viscosity of the material.

Table 3. Factorial design $3^{3}$ applied to rheological evaluation.

\begin{tabular}{cc}
\hline Factors & Levels \\
\hline Temperature $\left({ }^{\circ} \mathbf{C}\right)$ & 115 \\
& 125 \\
Moisture (\%) & 135 \\
& 20 \\
& 22 \\
Hydrolyzed protein flour $(\boldsymbol{\%})$ & 24 \\
& 15 \\
& 25 \\
\hline
\end{tabular}

\section{Results}

\subsection{Rheological behavior models}

The density values in the molten state at different percentages of hydrolyzed protein flour $(\mathrm{HPH})$ are presented in Table 4 . The results $(\mathrm{p}<0.05)$ did not show significant differences. Therefore, the mean melt density of $1.176 \mathrm{~g} / \mathrm{cm}^{3}$ was used to calculate the volumetric flow rate and the corresponding determination of the shear rate $(\gamma)$ in the evaluated treatments. The density obtained was lower than that obtained by researchers [18], who reported a density of $1.253 \mathrm{~g} / \mathrm{cm}^{3}$ in starch mixtures and isolated soy protein in different percentages.

Table 4. Density values in the fade state.

\begin{tabular}{cc}
\hline Treatment & Density in the molten state $\left(\mathbf{g} / \mathbf{c m}^{\mathbf{3}}\right)$ \\
\hline HPH 15 \% & $1.176 \pm 0.003$ \\
HPH 25 \% & $1.174 \pm 0.002$ \\
HPH 35 \% & $1.179 \pm 0.002$ \\
\hline
\end{tabular}

Table 5 shows the values of humidity, extrusion temperature and percentage of hydrolyzed protein flour of the 27 treatments studied, as well as the values of adjustment of their rheological behavior to the models of Law of Power, Casson and Bingham. For each model, the coefficient of determination $\left(R^{2}\right)$ and the standard error (E.M) were determined.

Table 5. Coefficient of determination $\left(\mathrm{R}^{2}\right)$ and standard error (E.M) values of the Power Law, Casson and Bingham models.

\begin{tabular}{|c|c|c|c|c|c|c|c|c|c|}
\hline \multirow{2}{*}{\multicolumn{4}{|c|}{ Treatments }} & \multicolumn{6}{|c|}{ Mathematical model } \\
\hline & & & & \multicolumn{2}{|c|}{ Power Law } & \multicolumn{2}{|c|}{ Casson } & \multicolumn{2}{|c|}{ Bingham } \\
\hline Sample & $\begin{array}{c}\text { Moisture } \\
(\%)\end{array}$ & $\begin{array}{c}\text { Temperature } \\
\left({ }^{\circ} \mathrm{C}\right)\end{array}$ & $\begin{array}{c}\text { Hydrolyz } \\
\text { ed } \\
\text { protein } \\
\text { flour }(\%)\end{array}$ & $\mathbf{R}^{2}$ & E.M & $\mathbf{R}^{2}$ & E.M & $\mathbf{R}^{2}$ & E.M \\
\hline $\mathrm{T} 1$ & 20 & 115 & 15 & 0.981 & 0.828 & 0.985 & 1.124 & 0.989 & 4.586 \\
\hline $\mathrm{T} 2$ & 22 & 115 & 15 & 0.952 & 1.938 & 0.943 & 1.803 & 0.934 & 3.600 \\
\hline $\mathrm{T} 3$ & 24 & 115 & 15 & 0.950 & 2.052 & 0.946 & 2.010 & 0.942 & 5.920 \\
\hline $\mathrm{T} 4$ & 20 & 125 & 15 & 0.994 & 0.523 & 0.997 & 0.617 & 0.998 & 1.956 \\
\hline
\end{tabular}




\begin{tabular}{cccccccccc}
\hline T5 & 22 & 125 & 15 & 0.995 & 0.675 & 0.996 & 0.892 & 0.996 & 2.040 \\
T6 & 24 & 125 & 15 & 0.999 & 2.315 & 0.999 & 2.550 & 1.000 & 2.441 \\
T7 & 20 & 135 & 15 & 0.989 & 1.017 & 0.989 & 1.133 & 0.990 & 0.759 \\
T8 & 22 & 135 & 15 & 0.985 & 0.607 & 0.982 & 0.566 & 0.979 & 0.508 \\
T9 & 24 & 135 & 15 & 0.978 & 6.561 & 0.979 & 6.258 & 0.980 & 3.040 \\
T10 & 20 & 115 & 25 & 0.976 & 5.185 & 0.974 & 5.409 & 0.972 & 61.313 \\
T11 & 22 & 115 & 25 & 0.999 & 6.627 & 0.999 & 7.134 & 0.999 & 41.409 \\
T12 & 24 & 115 & 25 & 0.957 & 4.080 & 0.960 & 4.701 & 0.962 & 20.725 \\
T13 & 20 & 125 & 25 & 0.994 & 8.089 & 0.994 & 8.573 & 0.993 & 58.775 \\
T14 & 22 & 125 & 25 & 0.986 & 5.626 & 0.985 & 5.782 & 0.983 & 24.038 \\
T15 & 24 & 125 & 25 & 0.978 & 4.338 & 0.977 & 4.587 & 0.977 & 9.310 \\
T16 & 20 & 135 & 25 & 0.981 & 9.473 & 0.981 & 10.147 & 0.981 & 33.067 \\
T17 & 22 & 135 & 25 & 0.986 & 5.814 & 0.986 & 5.905 & 0.985 & 13.208 \\
T18 & 24 & 135 & 25 & 0.997 & 3.932 & 0.997 & 4.104 & 0.997 & 0.635 \\
T19 & 20 & 115 & 35 & 0.965 & 5.103 & 0.958 & 5.792 & 0.951 & 176.116 \\
T20 & 22 & 115 & 35 & 0.940 & 2.596 & 0.932 & 2.865 & 0.924 & 99.746 \\
T21 & 24 & 115 & 35 & 0.996 & 2.292 & 0.994 & 2.578 & 0.991 & 79.431 \\
T22 & 20 & 125 & 35 & 0.981 & 3.976 & 0.979 & 4.647 & 0.976 & 145.233 \\
T23 & 22 & 125 & 35 & 0.965 & 2.693 & 0.969 & 3.150 & 0.972 & 98.550 \\
T24 & 24 & 125 & 35 & 0.946 & 2.334 & 0.952 & 2.557 & 0.956 & 66.145 \\
T25 & 20 & 135 & 35 & 1.000 & 3.632 & 0.999 & 4.140 & 0.998 & 95.237 \\
T26 & 22 & 135 & 35 & 0.958 & 2.411 & 0.965 & 2.816 & 0.971 & 58.995 \\
T27 & 24 & 135 & 35 & 0.991 & 2.341 & 0.992 & 2.627 & 0.992 & 49.114 \\
\hline
\end{tabular}

Table 5 presents three mathematical models for modeling the rheological behavior of the treatments studied in response to different processing conditions. The standard error is observed for each of the models, where the lowest values correspond to the Power Law model, especially to lower hydrolyzed flour content (15\%), being therefore the model that best fits the behavior of the experimental data. The coefficients of determination and standard error for the Casson and Bingham models that incorporate the term $\tau_{\text {or, }}$ have the least adjustment with respect to the experimental values. The power law model predominates in the analysis of viscosity behavior in extrusion processes [16]. Studies have been reported with Casson and Bingham models[17] ,evaluating mixtures of soybeans and corn for animal feed, obtaining as a result that the Power Law model presents a better fit. Other studies evaluated yield stress ( $\tau_{\text {or }}$ [ [19], [20] ,described in the Herschel-Bulkley model, obtaining as a result that this parameter is related to a structuring of the material, possibly by the presence of semicrystalline structures. However, these conformations should be destroyed during the shear treatment prior to the measurement of viscosity, generating controversy regarding the values of $\tau_{\text {or }}$ obtained, for which [21], propose to perform in-line measurement by X-ray diffraction to observe changes in crystallinity. In any of the cases reported above, the information was finally interpreted by the Power Law model, which for the case study was the one that presented the best fit, verified by the values of $\mathrm{R}^{2}$ and E.M. Similarly, Harper's rheological model, which explains the behavior of polymeric masses fused by extrusion, assumes for its use that the flow must be fully developed and that the fluid behaves according to the Power Law [7], [22].

Under the conditions of this experiment, the mixture presented a pseudoplastic behavior with a decrease in apparent viscosity as the shear rate increased, as indicated by the value of $n$ in the Power Law model. Various authors [10], [23],[24],[25] reported the use of the Power Law model to describe flow behavior using in-line and off-line rheology and experimental conditions similar to the present experiment. Similar results studied the rheological behavior of a formulation for animal feed [17], and studied the rheological behavior of mixtures of native and pregelatinized wheat starch, results that indicate that the rheological behavior of the treatments is determined by the properties of starch, the majority component of the formulations [23]. The dependence of the viscosity of the molten polymer on the velocity is related to the molecular reduction at the higher shear rate, 
and the further away from the value of $n$ from 1 , the further away it moves away from a behavior of a Newtonian fluid, being more sensitive to the shear rate [10],[12]. According to the Power Law model, the analysis of variance was performed for the response variables $n$ and Klp, as shown in Table 6 .

Table 6. Analysis of variance model of Power Law.

\begin{tabular}{|c|c|c|c|c|}
\hline \multirow{2}{*}{ Fountain } & \multicolumn{2}{|c|}{$n$} & \multicolumn{2}{|c|}{$K_{l p}\left(P_{a . s^{n}}\right)$} \\
\hline & $\mathbf{F}$ & $\mathbf{P}$ & $\mathbf{F}$ & $\mathbf{P}$ \\
\hline Moisture & 159.39 & 0.000 & 317.33 & 0.000 \\
\hline Temperature & 251.89 & 0.000 & 506.18 & 0.000 \\
\hline НРН & 1470.92 & 0.000 & 2355.22 & 0.000 \\
\hline Moisture*Temperature & 1.46 & 0.242 & 19.53 & 0.000 \\
\hline Moisture*HPH & 7.34 & 0.000 & 105.57 & 0.000 \\
\hline Temperature*HPH & 4.54 & 0.006 & 175.12 & 0.000 \\
\hline Moisture*Temperature*HPH & 1.42 & 0.233 & 8.24 & 0.000 \\
\hline
\end{tabular}

According to the assumptions of normality, the values of $\mathrm{F}$ and $\mathrm{P}$ estimated in the ANOVA $(p<0.05)$ indicate that the factors hydrolyzed protein flour, temperature, and humidity have a significant influence on the values of $n$ and $k$, being the hydrolyzed protein flour the aspect of most significant impact.

Table 7 shows the mean values and standard deviation of flow behavior index $(n)$ and consistency index $(K l p)$ for the treatments studied. The mean comparison test $(\mathrm{p}<$ 0.05 ) shows 13 different groups for the variable flow behavior index $(n)$. It is observed that in all cases, the treatments are affected by temperature, humidity, and the content of hydrolyzed protein flour.

Table 7. Mean values and standard deviation of flow behavior index $(n)$ and consistency index $\left(K_{l p}\right)$ for the studied treatments.

\begin{tabular}{ccc}
\hline Sample & Flow behavior index $(\boldsymbol{n})$ & $\begin{array}{c}\text { Consistency Index } \\
\left(\boldsymbol{K}_{\text {lp }}, \mathbf{P a .} . \mathbf{s}^{\mathrm{n}}\right)\end{array}$ \\
\hline T1 & $0.6108 \pm 0.0009^{\mathrm{h}}$ & $982 \pm 10^{\mathrm{e}}$ \\
T2 & $0.72 \pm 0.04^{\mathrm{e}}$ & $868 \pm 124^{\mathrm{f}}$ \\
T3 & $0.743 \pm 0.009^{\mathrm{d}}$ & $561 \pm 29^{\mathrm{g}}$ \\
T4 & $0.67 \pm 0.03^{\mathrm{f}}$ & $535 \pm 23^{\mathrm{g}}$ \\
T5 & $0.74 \pm 0.03^{\mathrm{d}}$ & $408 \pm 57^{\mathrm{h}}$ \\
T6 & $0.82 \pm 0.02^{\mathrm{b}}$ & $322 \pm 27^{\mathrm{i}}$ \\
T7 & $0.79 \pm 0.02^{\mathrm{c}}$ & $333 \pm 20^{\mathrm{i}}$ \\
T8 & $0.849 \pm 0.005^{\mathrm{b}}$ & $176 \pm 2^{\mathrm{j}}$ \\
T9 & $0.976 \pm 0.012^{\mathrm{a}}$ & $159 \pm 9^{\mathrm{j}}$ \\
T10 & $0.62 \pm 0.02^{\mathrm{g}}$ & $1474 \pm 132^{\mathrm{e}}$ \\
T11 & $0.68 \pm 0.02^{\mathrm{f}}$ & $992 \pm 81^{\mathrm{e}}$ \\
T12 & $0.73 \pm 0.03^{\mathrm{d}}$ & $585 \pm 99^{\mathrm{g}}$ \\
T13 & $0.673 \pm 0.009^{\mathrm{f}}$ & $1087 \pm 49^{\mathrm{e}}$ \\
T14 & $0.71 \pm 0.03^{\mathrm{e}}$ & $677 \pm 108^{\mathrm{g}}$ \\
T15 & $0.800 \pm 0.013^{\mathrm{b}}$ & $334 \pm 22^{\mathrm{i}}$ \\
T16 & $0.76 \pm 0.02^{\mathrm{c}}$ & $666 \pm 66^{\mathrm{g}}$ \\
T17 & $0.81 \pm 0.03^{\mathrm{b}}$ & $431 \pm 69^{\mathrm{h}}$ \\
T18 & $0.885 \pm 0.006^{\mathrm{a}}$ & $207 \pm 5^{\mathrm{j}}$ \\
T19 & $0.372 \pm 0.012^{\mathrm{m}}$ & $6362 \pm 371^{\mathrm{a}}$ \\
T20 & $0.381 \pm 0.007^{1}$ & $4472 \pm 142^{\mathrm{b}}$ \\
T21 & $0.441 \pm 0.004^{\mathrm{k}}$ & $2299 \pm 43^{\mathrm{d}}$ \\
\hline
\end{tabular}




\begin{tabular}{ccc}
\hline T22 & $0.393 \pm 0.003^{1}$ & $4125 \pm 69^{\mathrm{b}}$ \\
T23 & $0.42 \pm 0.02^{\mathrm{k}}$ & $2983 \pm 302^{\mathrm{c}}$ \\
T24 & $0.458 \pm 0.013^{\mathrm{k}}$ & $2188 \pm 147^{\mathrm{d}}$ \\
T25 & $0.47 \pm 0.02^{\mathrm{j}}$ & $2453 \pm 290^{\mathrm{c}}$ \\
T26 & $0.513 \pm 0.013^{\mathrm{j}}$ & $1542 \pm 103^{\mathrm{e}}$ \\
T27 & $0.554 \pm 0.005^{\mathrm{i}}$ & $1014 \pm 31^{\mathrm{e}}$ \\
\hline
\end{tabular}

Different superscript letters in the same column indicate significant differences between treatments $(\mathrm{p}<0.05)$.

The data obtained show that as the percentage of humidity and temperature increases, the value of $n$ increases, and the importance of $K_{l p}$ decreases. Both the rise in water and the temperature rise reduces the resistance to the flow of the matrices. Conversely, when the percentage of hydrolyzed flour in the formulation increases, the value of $n$ becomes lower, and the importance of Klp increases. This may be because hydrolyzed proteins, despite having a plasticizing effect due to their low molecular weight, could also be part of the continuous matrix when unfolding and interacting with other proteins or starch, thereby increasing the consistency index [26] going from values between $159-982$ Pa.sn, for $15 \%$ of protein flour, to values between 1014- 6362 Pa.sn, for $35 \%$ of protein flour. This behavior has a close relationship with the amphipathic properties of proteins and according to the amino acid composition of hydrolyzed protein flour. Table 7, presents amino acids with positive charges such as histidine and arginine and damaging costs of amino acids such as aspartic acid and glutamic acid. According to the hydropathy index, it is also possible to identify amino acids with hydrophobic solid characters such as isoleucine (4.5), valine (4.2) and leucine (3.8) and hydrophiles such as arginine (-4.5), lysine (-3.9), aspartic acid (-3.5), glutamic acid (-3.5) and histidine (-3.2) [28] conferring on them electrical properties conducive to interacting with each other and with the other components of the matrix during extrusion, forming various discontinuous or semi-continuous structures, modifying the functionality of proteins.

The treatments T9 and T18, described in Table 4.7 letter (a) parameter $n$, letter (j) parameter Klp presented the highest values of $\mathrm{n}$ and close to 1 , as well as the lowest values of Klp, which indicates a behavior that approaches a Newtonian fluid, being the treatments that have higher moisture and temperature content. The moisture content combined with the increase in temperature increased mobility in the extrusion barrel [30],behavior reflected in the value of $K_{l p}$. Treatments 19 and 20 [letters $(k, l)$ parameter $n$, letters $(\mathrm{a}, \mathrm{b})$ parameter $\mathrm{k}]$, show the lowest $n$ values of the experiment, as well as the highest values of $K_{l p}$,corresponding to the treatments with higher content of hydrolyzed protein flour, indicating the presence of crosslinking interactions that will influence pseudoplastic behavior, an effect marked by the increase in the incorporation of hydrolyzed protein flour, which contributes to the stability of the final product forming networks of intermolecular bonds such as hydrogen and ionic bonds [29], presenting the lowest values of $n$ and the highest value of $k$. Studies reported values of $n=0.246$ [3], in extruded diets for fish with high protein content, indicating a high degree of thinning by shear, behavior similar reported that an increase in protein in the formulation decreases the value of $n$ ,behavior similar to that obtained in the present study [15].

Table 8 shows the parameters of harper's model. The equation presents the assumption that the apparent viscosity $(n)$ has a dependence on the Power Law with the shear rate, an Arrhenius dependence on temperature $(\mathrm{T})$ and an exponential dependence on moisture content (MC) $\gamma$ [3], assuming that the flow is fully developed through the capillary and is in laminar regime, there is no viscous dissipation or slippage of the material in the wall, there is no loss of pressure at the end of the capillary and the fluid behaves according to the Power Law [7],[22]. 
Table 8. Harper model parameters for hydrolyzed protein flour.

\begin{tabular}{|c|c|c|c|c|c|c|}
\hline $\begin{array}{c}\text { HYDROLY } \\
\text { ZED } \\
\text { PROTEIN } \\
\text { FLOUR }(\%)\end{array}$ & $\begin{array}{c}\boldsymbol{K}_{l p} \\
\left(\boldsymbol{P a} . s^{n}\right)\end{array}$ & $\begin{array}{c}n \\
(\text { Pa.s })\end{array}$ & $\begin{array}{c}E / R \\
(K)\end{array}$ & $\boldsymbol{b}$ & $\mathbf{R}^{2}$ & EQUATION \\
\hline 15 & 1,00 & 0,79 & 2563 & $-0,82$ & 0,89 & $\eta=1,00^{*}(\gamma)^{-0,21} e^{\left[\left(2563^{*} T T\right)-\left(0,82^{*} M C\right)\right]}$ \\
\hline 25 & 359,96 & 0,65 & 1410 & $-11,91$ & 0,95 & $\eta=359,96 *(\gamma)^{-O 35} e^{[(1410 * T)-(11,92 * M C)]}$ \\
\hline 35 & 1745,86 & 0,48 & 1208 & $-11,82$ & 0,89 & $\eta=1745,86 *(\gamma)^{-0,52} e^{[(1208 * T)-(11,82 * M C)]}$ \\
\hline
\end{tabular}

The models described for the different percentages of inclusion of hydrolyzed protein flour $(15,25$ and $35 \%)$, show values with positive sign for the term (E / R), indicating that the increase in viscosity is related to the decrease in the temperature of the product in the range of temperatures studied [3]. The increase in the consistency index $K_{l p}$, is related to the proportional increase of hydrolyzed protein flour, behavior possibly related to a greater interaction between the macromolecules present in the mixture [31]. The equations show an $\mathrm{R}^{2}$ between 0.89 and 0.95 , which allows the model to fit the data and the possibility of using the equation as a data design and estimation tool under similar test conditions.

\subsection{Effect of temperature}

Figure 2 shows the effect of temperature variation on the shear stress and apparent viscosity in the treatments studied with a moisture content of $22 \%$. The shear stress and apparent density have an opposite behavior compared to the shear rate, and as the temperature increases, the shear stress and the evident viscosity decrease. It is known that an increase in temperature results in a reduction of the viscosity of the molten polymer [13],[20],[12]. During the extrusion process, polymers such as starch and protein can present different degrees of transformation and molecular degradation under a thermomechanical treatment such as extrusion cooking [32], is reported that the increase in speed can reduce viscosity and although the average residence time is reduced, the intensity of mechanical treatment, transformation, and macromolecular degradation increases and therefore, lower viscosity in a molten state, being more critical at a lower temperature [14].

A

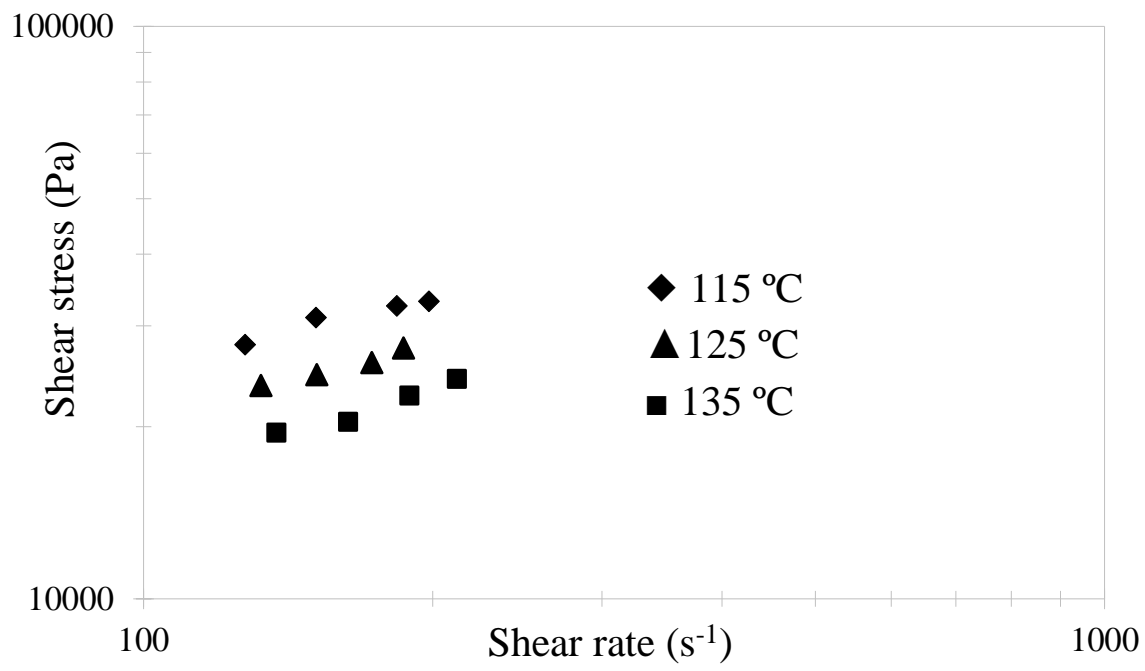

B 


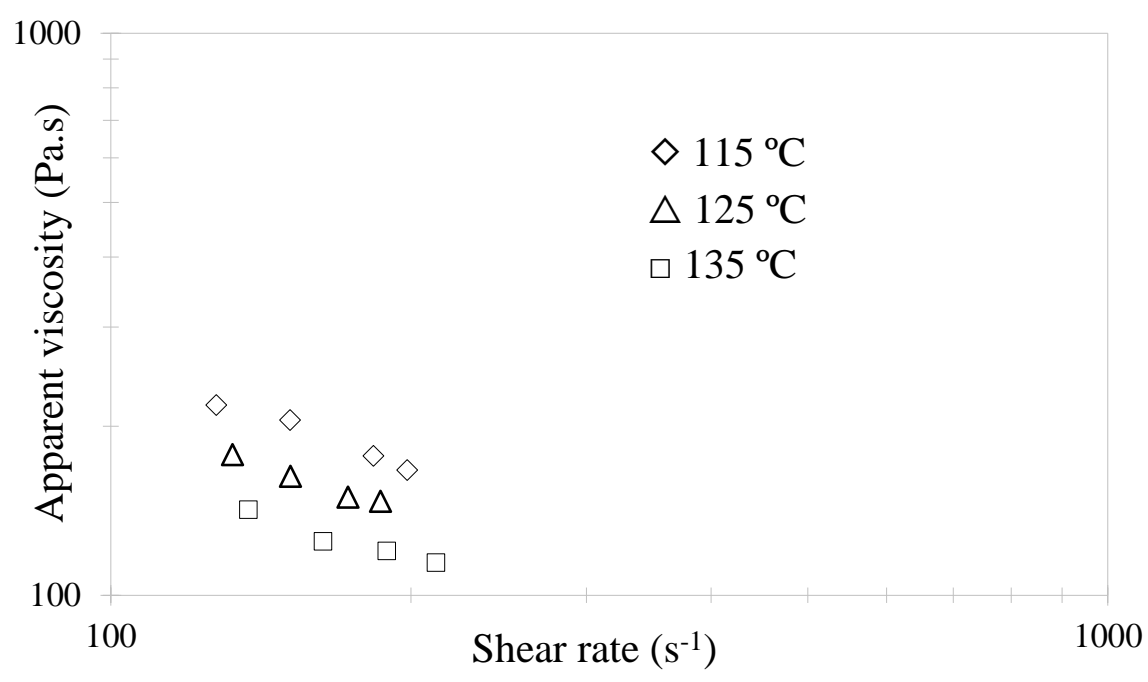

Figure 2. Effect of temperature variation on shear stress (a) and apparent viscosity (b) in the treatments studied with a moisture content of $22 \%$ and $35 \% \mathrm{HPH}$.

Increasing the temperature increases the molecular degradation, decreasing its size and growing mobility by increasing kinetic energy and reducing the volume occupied by each molecule [33]. Similarly, an increase in temperature generates an increase in the gelatinization of starch [10]. Usually, this would lead to an increase in viscosity. However, in the analyzed treatments, it is observed that the viscosity decreases, suggesting that the effect of molecular degradation and the increase in kinetic energy are more significant than gelatinization on the change in thickness, as shown in Figure 2.

The temperatures used in the extrusion process led to denaturation of proteins due to the irreversible alteration of non-covalent interactions (hydrophobic and electrostatic), wherein the secondary, tertiary, and quaternary structures of the proteins will weaken due to temperature and shear forces [33]. The proteins will unfold and align as the material travels through the extruder screw and the head [26]. As shown in Table 7, the value of $n$ approaches one at a higher temperature, behavior attributed to a decrease in the size of starch and protein molecules generated by fractionation at high temperatures [11].

\subsection{Effect of humidity}

Figure 3 shows the effect of the variation of moisture content on the shear stress and apparent viscosity in the treatments studied with a protein flour content of $35 \%$. It is observed that the increase in moisture content caused a decrease in both shear stress and apparent viscosity. 


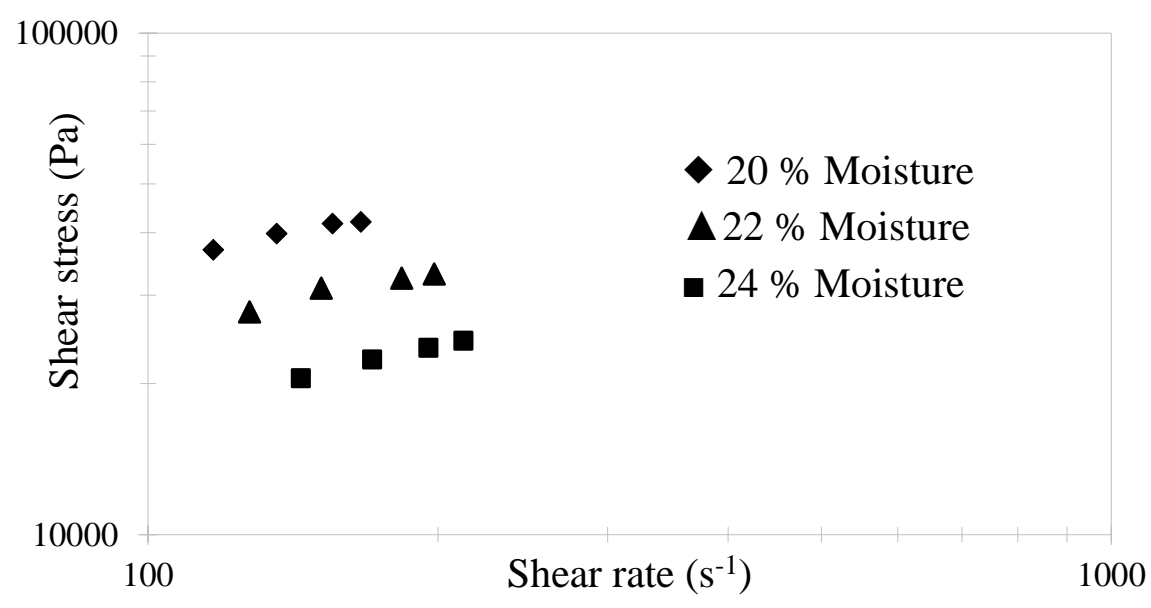

b

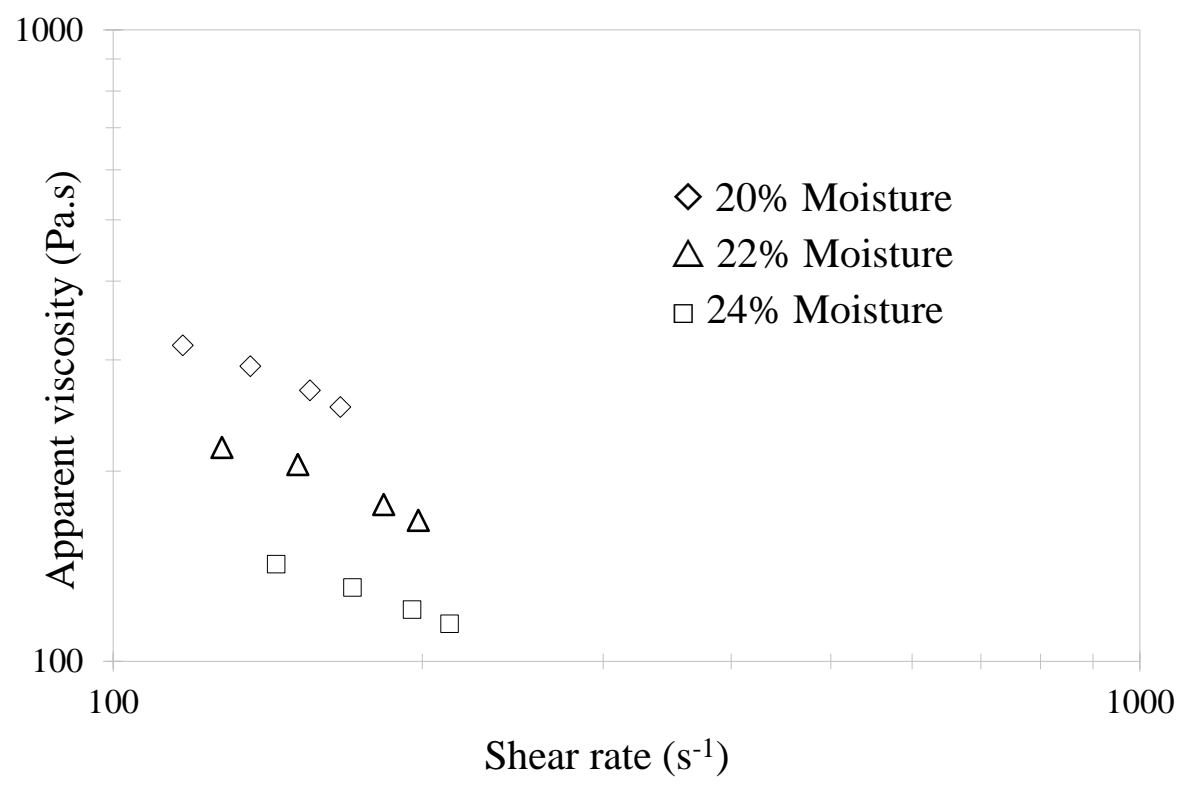

Figure 3. Effect of the variation of moisture content on the shear stress (a) and apparent viscosity (b) in the treatments studied with a protein flour content of $35 \%$ and $115{ }^{\circ} \mathrm{C}$.

According to Table 7, when the moisture content decreases, from 24 to $20 \%$, the consistency index (Klp) increases from values between 159-2299 Pa.s to values between 3336362 Pa.s., indicating that the Moisture affects the apparent viscosity of the treatments. Similar results were found where they studied the effect of the extrusion parameters on the rheological behavior of corn using an in-line slit die rheometer, reporting that the viscosity, specific mechanical energy, torque, and pressure in the head decreased with increasing humidity of the matrices, consistent with an increase in the molecular mobility of the treatments [10],[12]. On the other hand, it is expected that at lower moisture contents, both starch molecules and proteins suffer more damage, destructuring the molecules causing Maillard reactions Error! Reference source not found., minimizing this effect at moisture contents higher than $25 \%$ [26].

The gelatinization of starch during extrusion occurs at a humidity lower than $30 \%$, lower compared to other ways of processing food [34]. The limitation of the water proportion between 20 and $24 \%$ in the extrusion-cooking process, conditions in which the present test was developed, affected the macromolecules present in the processed 
mixture, possibly obtaining starch molecules in different gelatinization stages. Such as gelatinized but not swollen granules, swollen and gelatinized granules, and even wholly damaged granules. Therefore, the interaction between moisture content and temperature, affecting molecular transformation at different levels [35]. An increase in the moisture content and the extrusion temperature promotes molecular mobility, with the corresponding decrease in viscosity as shown in figure 4.3. On the one hand, the temperature increases the system's energy, and the water acts as a solvent. And plasticizer making it easy for macromolecules to unfold [11],[16], [35],[24].

\subsection{Effect of hydrolyzed protein flour}

Figure 4 shows the effect of the variation of the hydrolyzed protein flour content on the shear stress and apparent viscosity at $125^{\circ} \mathrm{C}$. Therefore, as the shear rate increases, the shear stress increases, and the viscosity decreases. Furthermore, as the amount of hydrolyzed flour in the formulation increases, the shear stress and viscosity values tend to grow. Due to the low molecular weight of the peptides from hydrolyzed protein flour, it could be inferred that they tend to be located between the starch chains, acting both as plasticizers of the matrix and as crosslinking agents between the different extrudate fractions (free sugars, dextrins, peptides of various molecular weights) [29]. Starch, for its part, as the majority component in the evaluated matrix $(52 \%)$, interacts directly with proteins since they contain several hydrophilic groups such as $-\mathrm{OH},-\mathrm{NH} 2,-\mathrm{COOH}$, and $-\mathrm{SH}$ in the side alkyl chains, which they can form bonds with starch, affecting the rheological properties of the material [36]. Generally, an increase in hydrolyzed protein slightly increases the viscosity shown in figure 4 .

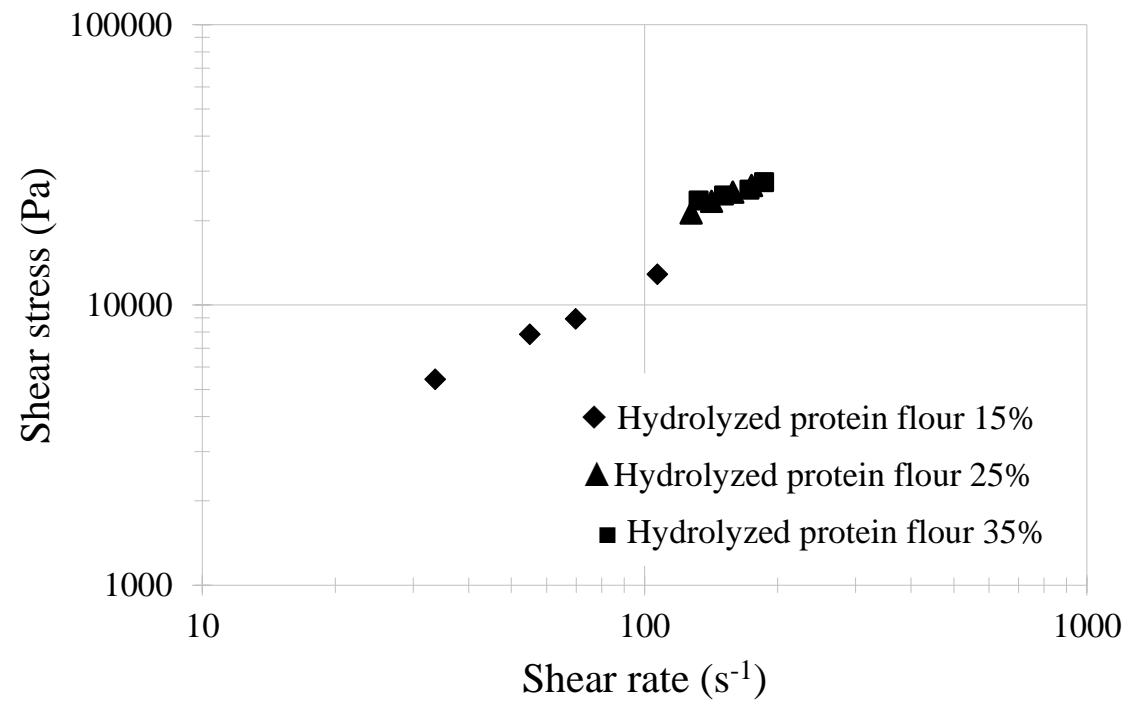

b 


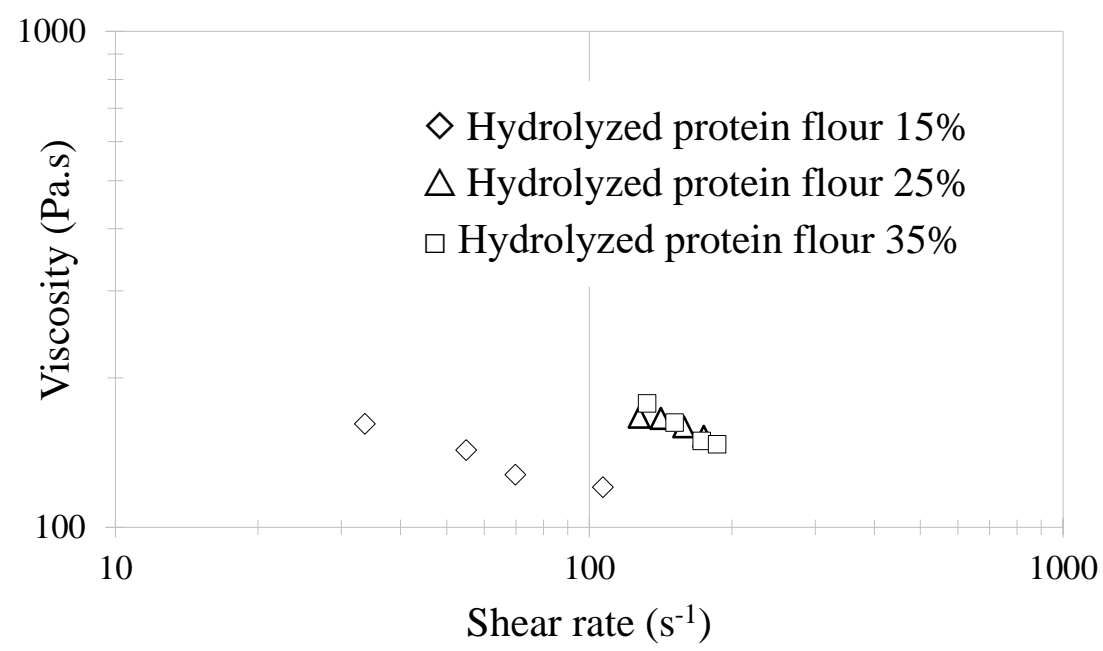

Figure 4. Effect of variation in hydrolyzed protein meal content on shear stress (a) and apparent viscosity (b) at $125^{\circ} \mathrm{C}$ and $22 \%$ moisture.

Hydrolyzed protein flour content, as shown in Figure 4. Peptides that promote the sliding of starch chains would act as plasticizers, while peptides with exposed amino acid residues with the ability to react with dextrin and sugar end groups would act as crosslinking agents, reducing molecular mobility and therefore generating a viscosity increase [29], according to the results obtained. The increase in viscosity of the treatments studied suggests that crosslinking has a more significant effect on the viscosity of the treatments than the possible plasticizing effect of the low molecular weight peptides, which would also be consistent with the increase in shear stress promoted by the rise.

Similar studies reported the increase in viscosity due to gel formation under extrusion conditions, related to the denaturation of myosin, mainly responsible for gelation, aggregation, and various forms of interaction phenomena [37],[38], forming a three-dimensional network that the terminal groups of the molecules can establish via hydrophobic interactions, as well as disulfide bridges. The exposed hydrophilic amino acid residues will be free to interact and react with the other components, such as sugar residues and the aqueous medium. In contrast, the hydrophobic amino acid residues will align, forming intermolecular hydrophobic bonds, trapping apolar molecules inside, such as lipids or air present in formulations [26]. The protein-starch interactions due to the formation of amylose-protein complexes [39],[40], the number of insoluble aggregates formed [40], as well as the crosslinking of the peptides during Maillard reactions [41] could affect increasing the viscosity and resistance to flow of the material, requiring greater torque during the extrusion process with the addition of hydrolyzed protein flour. Also, studied the effect of the expansion of salt and sugar on the extrusion process of wheat and corn mixtures and reported that when the interactions between macromolecules (starch chains) were improved, the viscosity of the melt requiring a more significant amount of energy to push the molten matrix through the screw and this, in turn, generated more considerable pressure in the head [41].

According to the above, it is possible to infer that the increase in the concentration of hydrolyzed protein generates an increase in the interactions of the macromolecules present through the crosslinking of polymeric chains and the presence of high molecular weight proteins contained in fishmeal. Conventional water lowers the free water in the system by forming aggregates, as discussed above. Similar results studied the effect of hydrolyzed fish muscle on the rice flour extrusion process, observing that its addition tends to increase the values of specific mechanical energy slightly, attributing this 
phenomenon to the presence of low molecular weight peptides that cause compaction during extrusion, increasing energy requirements per unit of extruded mass [43],[44]. When the mixture is exposed to thermomechanical treatments such as extrusion, the protein may experience an unfolding of packed structures or separation of the protein into subunits [40], aggregation [33] and crosslinking [31], behavior related to the increase in shear stress, as observed in the results described above.

\section{Conclusions}

The slit dies to type in-line rheometer allowed to assess the rheological behavior of the material, obtaining information on the actual processing condition, observing that the evaluated treatments conform to the Power Law, where an increase in the shear rate decreases the viscosity of the material, corresponding to a pseudoplastic behavior. The incorporation of hydrolyzed protein flour has a significant effect on the value of $n$ and Klp, increasing the viscosity with the increase in the percentage of inclusion of $\mathrm{HPH}$, suggesting the formation of a series of crosslinking reactions, formation of three-dimensional networks, hydrophobic bonds, and Maillard reactions, with response in process variables such as the increase in specific mechanical energy. The models obtained for the prediction of the viscosity are adjusted to the system's changes in sheer speed, temperature, and humidity.

Acknowledgments: : The authors thank the Universidad Nacional del Cauca and the Universidad de Cartagena (Colombia) to support the development of this work regarding laboratory, software use, and time for their researchers.

Conflicts of Interest: The authors declare they have no conflicts of interest.

Author Contributions: Conceptualization, Rodrigo Ortega-Toro; Data curation, José Hoyos-Concha; Formal analysis, José Hoyos-Concha; Funding acquisition, José Hoyos-Concha; Investigation, José Hoyos-Concha; Methodology, José Hoyos-Concha; Project administration, José Hoyos-Concha and Hector Villada-Castillo; Resources, José Hoyos-Concha, Hector Villada-Castillo and Alejandro Fernández-Quintero; Software, José Hoyos-Concha and Rodrigo Ortega-Toro; Supervision, Hector Villada-Castillo and Alejandro Fernández-Quintero; Validation, José Hoyos-Concha, Hector Villada-Castillo and Alejandro Fernández-Quintero; Visualization, José Hoyos-Concha and Alejandro Fernández-Quintero; Writing - original draft, José HoyosConcha and Rodrigo Ortega-Toro; Writing - review \& editing, José Hoyos-Concha and Rodrigo Ortega-Toro.

\section{References}

[1] Mercier, C., Linko, P. (Pekka), \& Harper, J. M. Extrusion cooking. American Association of Cereal Chemists 1989.

[2] Roberts, I. In-line and on-line rheology measurement. Instrumentation and sensors for the food industry (Second Edi). Woodhead Publishing Limited 2001. doi: 10.1533/9781855736481.1.403

[3] Lam, C. D., \& Flores, R. a. Effect of Particle Size and Moisture Content on Viscosity of Fish Feed, Cereal Chemistry. 2003, 20-24. doi: 10.1094/CCHEM.2003.80.1.20

[4] Choudhury, Gour S., and Binoy K. Gogoi. "Extrusion processing of fish muscle: a review." Journal of aquatic food product technology. 1996, 37-67. doi: 10.1300/J030v04n04_05

[5] Van Den Einde, R. M. "Molecular breakdown of corn starch by thermal and mechanical effects." Carbohydrate Polymers. 2004, 56(4) 415-422. doi:10.1016/j.carbpol.2004.03.006

[6] Meuser, F., B. Vonlengerich, and F. Kohler. "The influence of extrusion parameters on the functional-properties of wheatstarch." Starke. 1982, 366-372. doi: 10.1002/star.19820341103

[7] Sandoval, Angélica P., Imad FARHAT, and Alejandro Fernández. "Rheological modeling of cassava (Manihot esculenta Cranz) starches and flours during extrusion process." Vitae. 2007, 14, (1) 06-15. 
[8] Bhattacharya, S., Das, H., \& Bose, A. N. Rheological behaviour during extrusion of blends of minced fish and wheat flour. Journal of Food Engineering. 1992, 15(2), 123-137. doi:10.1016/0260-8774(92)90029-6

[9] Harper, J. M. "Extrusion of Foods CRC Press." Boca Raton, FL 1981, 3-6.

[10]Li, P. X., Campanella, O. H., \& Hardacre, A. K. Using an In-Line Slit-Die Viscometer to Study the Effects of Extrusion Parameters on Corn Melt Rheology. Cereal Chemistry. 2004, 81(1), 70-76. doi:10.1094/cchem.2004.81.1.70

[11] Vergnes, B., Della Valle, G., \& Tayeb, J. A specific slit die rheometer for extruded starchy products. Design, validation and application to maize starch. Rheologica Acta. 1993, 32(5), 465-476. doi:10.1007/BF00396177

[12] Xie, F., Halley, P. J., \& Avérous, L. Rheology to understand and optimize processibility, structures and properties of starch polymeric materials. Progress in Polymer Science (Oxford). 2012, 37(4), 595-623. doi: 10.1016/j.progpolymsci.2011.07.002

[13] Martin, O., Averous, L., \& Della Valle, G. In-line determination of plasticized wheat starch viscoelastic behavior: Impact of processing. Carbohydrate Polymers. 2003, 53(2), 169-182. doi:10.1016/S0144-8617(03)00040-7

[14] Senouci, A., \& Smith, A. C. An experimental study of food melt rheology - I. Shear viscosity using a slit die viscometer and a capillary rheometer. Rheologica Acta. 1988, 27(5), 546-554. doi:10.1007/BF01329355

[15] Bhattacharya, M., \& Hanna, M. A. Viscosity modelling of dough in extrusion. International Journal of Food Science \& Technology. 1986, 21(2), 167-174. doi:10.1111/j.1365-2621.1986.tb00438.x

[16]Xie, F., Yu, L., Su, B., Liu, P., Wang, J., Liu, H., \& Chen, L. Rheological properties of starches with different amylose/amylopectin ratios. Journal of Cereal Science. 2009, 49(3), 371-377. doi:10.1016/j.jcs.2009.01.002

[17] Fraiha, M., Biagi, J. D., \& Carlos De Oliveira Ferraz, A. Rheological behavior of corn and soy mix as feed ingredients. Ciência E Tecnologia de Alimentos. 2011, 31(1), 129-134. doi:10.1590/S0101-20612011000100018

[18] Ralston, B. E., \& Osswald, T. A. Viscosity of soy protein plastics determined by screw-driven capillary rheometry. Journal of Polymers and the Environment. 2008, 16(3), 169-176. doi:10.1007/s10924-008-0098-3

[19] Bastioli, C., Bellotti, V., \& Rallis., A. Microstructure and melt flow behavior of a starch-based polymer. Rheologica Acta. 1994, 33(1), 307-316. doi:10.1007/BF01974447

[20] Della Valle, G., Vergnes, B., \& Lourdin, D. Viscous properties of thermoplastic starches from different botanical origin. International Polymer Processing. 2007, 22(5), 471-479. doi:10.3139/217.2057

[21] Tuladhar, T. R., \& Mackley, M. R. Experimental observations and modelling relating to foaming and bubble growth from pentane loaded polystyrene melts. Chemical Engineering Science. 2004, 59(24), 5997-6014. doi:10.1016/j.ces.2004.07.054

[22] Akdogan, H. High moisture food extrusion. International Journal of Food Science \& Technology. 1999,34, $195-207$. doi:10.1046/j.1365-2621.1999.00256.x

[23] Alavi, S. H., Chen, K. H., \& Rizvi, S. S. H. Rheological characteristics of intermediate moisture blends of pregelatinized and raw wheat starch. Journal of Agricultural and Food Chemistry. 2002, 50(23), 6740-6745. doi:10.1021/jf011662q

[24] Padmanabhan, M., \& Bhattacharya, M. Planar extensional viscosity of corn meal dough. Journal of Food Engineering. 1993, 18(4), 389-411. doi:10.1016/0260-8774(93)90054-N

[25] Singh, N., \& Smith, A. C. Rheological behaviour of different cereals using capillary rheometry. Journal of Food Engineering. 1999, 39(2), 203-209. doi:10.1016/S0260-8774(98)00165-4 
[26] Camire, M. E. Protein Functionality Modification by Extrusion Cooking I. Journal of the American Oil Chemists'Society. 1991, 68(3), 200-205. doi:10.1007/BF02657770

[27] Guy, Robin. "Raw materials for extrusion cooking." Extrusion cooking. Woodhead Publishing, 2001. doi:org/10.1533/9781855736313.1.5

[28] Nelson, D. L., \& Cox, M. M. (2008). Absolute Ultimate Guide for Lehninger. Principles of Biochemistry. $2008,600$.

[29] Samuelsen, T. A., Mjøs, S. A., \& Oterhals, Å. Impact of variability in fishmeal physicochemical properties on the extrusion process, starch gelatinization and pellet durability and hardness. Animal Feed Science and Technology. 2013, 179(1-4), 7784. doi: 10.1016/j.anifeedsci.2012.10.009

[30] Choudhury, G. S., \& Gautam, A. Hydrolyzed Fish Muscle as a Modifier of Rice Flour Extrudate Characteristics Food Engineering and Physical Properties. Food Engineering and Physical Properties. 2003, 68(5), $1713-1721$. doi:10.1111/j.1365-2621.2003.tb12318.x

[31] Oterhals, A., \& Samuelsen, T. A. Plasticization effect of solubles in fishmeal. Food Research International 2015, 69, 313321. doi:10.1016/j.foodres.2014.12.028

[32] Lević, J., Olivera, E. M., Mr, Đ., Sredanović, S., \& Kokić, B. Heat treatments in animal feed processing. In Extrusion technology in feed and food processing. 2010, 19-21

[33]Zimonja, O. Effects of Chemical Changes of Starch and Proteins on Physical Pellet Quality in Respect to Extrusion Technology. 2015.

[34] Singh, S., Gamlath, S., \& Wakeling, L. Nutritional aspects of food extrusion: A review. International Journal of Food Science and Technology. 2007, 42(8), 916-929. doi:10.1111/j.1365-2621.2006.01309.x

[35]Fallahi, P., Muthukumarappan, K., \& Rosentrater, K. A. Functional and structural properties of corn, potato, and cassava starches as affected by a single-screw extruder. International Journal of Food Properties. 2015, 1-56. doi:10.1080/10942912.2015.1042112

[36] Sopade, P. A., Hardin, M., Fitzpatrick, P., Desmee, H., \& Halley, P. Macromolecular interactions during gelatinisation and retrogradation in starch-whey systems as studied by rapid visco-analyser. International Journal of Food Engineering. 2006, 2(4), 1-15. doi:10.2202/1556-3758.1074

[37] Gilleland, G. M., Lanier, T. C., \& Hamann, D. D. Covalent Bonding in Pressure-Induced Fish Protein Gels. Journal of Food Science. 1997, 62(4), 713-733. doi:10.1111/j.1365-2621.1997.tb15442.x

[38] Stone, A. P., \& Stanley, D. W. Mechanisms of fish muscle gelation. Food Research International. 1992, $25(5), 381-388$. doi:10.1016/0963-9969(92)90113-J

[39] Allen, K. E., Carpenter, C. E., \& Walsh, M. K. Influence of protein level and starch type on an extrusion-expanded whey product. International Journal of Food Science and Technology. 2007, 42(8), 953-960. doi:10.1111/j.13652621.2006.01316.x

[40] Day, L., \& Swanson, B. G. Functionality of protein-fortified extrudates. Comprehensive Reviews in Food Science and Food Safety. 2013, 12(5), 546-564. doi:10.1111/1541-4337.12023

[41]Lan, X., Liu, P., Xia, S., Jia, C., Mukunzi, D., Zhang, X., ... Xiao, Z. Temperature effect on the non-volatile compounds of 
Maillard reaction products derived from xylose-soybean peptide system: Further insights into thermal degradation and crosslinking. Food Chemistry. 2010, 120(4), 967-972. doi:10.1016/j.foodchem.2009.11.033

[42]Pitts, K. F., Favaro, J., Austin, P., \& Day, L.. Co-effect of salt and sugar on extrusion processing, rheology, structure and fracture mechanical properties of wheat-corn blend. Journal of Food Engineering. 2014, 127, 58-66. doi:10.1016/j.jfoodeng.2013.11.026

[43] Choudhury, G. S., \& Gautam, A. Effects of hydrolysed fish muscle on intermediate process variables during twin-screw extrusion of rice flour. LWT - Food Science and Technology. 2003, 36(7), 667-678. doi:10.1016/S0023-6438(03)00087-2

[44] Choudhury, G. S., \& Gautam, A. Hydrolyzed Fish Muscle as a Modifier of Rice Flour Extrudate Characteristics Food Engineering and Physical Properties. Food Engineering and Physical Properties. 2003, 68(5), $1713-1721$. doi:10.1111/j.1365-2621.2003.tb12318.x 